and, what is most remarkable, the radio-activity was removed by washing with water. The solution contains an emanation, for on bubbling air through it, and cooling the gas with liquid air, the issuing gaseous air is only feebly active; the main part of the activity was retained in the cooled bulb. This substance can be carried into an electroscope by a current of air, and when the current passes, the electroscope is discharged; but the period of decay of the emanation is very short, and in that respect resembles the emanation from actinium.

The research is not sufficiently advanced to permit of a complete account of the other products, but it may be mentioned that from the solution which has lost all emanating power further active products are obtainable, some of which are precipitable along with mercurous chloride, some along with mercuric sulphide, some with ferric oxide, and some with barium sulphate. The behaviour is different, according as potash- or soda-glass is used. That this is not a case of a body being thrown down by any precipitant has been abundantly proved; for example, precipitation along with mercurous chloride or sulphide failed to remove the activity from one sample, while the precipitation of ferric hydroxide in the solution completely threw down the radioactive material. There appear to be several radio-active bodies present which can be separated by the ordinary processes of qualitative analysis.

These substances, it must be remembered, are the products of $\beta$ and $\gamma$ rays in conjunction with the material on which they impinge. A silver crucible, too, becomes radio-active on the exposed surface only when placed in the path of $\beta$ rays. It is important to note that these changes are not due to the material having been in contact with radium or any of its products; they are solely due to the $\beta$ and possibly to the $\gamma$ rays. The order of the activity is the same as that of $x$ milligram of old uranium oxide, $\mathrm{U}_{3} \mathrm{O}_{8}$.

$$
\text { WILLIAM RAMSAY. }
$$

University College, London, July 30.

$$
\text { W. Ternent Cooke. }
$$

Atomic Structure in the Light of Secondary Spectra. In making some determinations of the capacity necessary just to produce secondary spectra, I have found that this critical capacity increases very rapidly with decreasing wave-length. The primary spectrum does not go over suddenly as the critical capacity is reached, but the red and yellow portions go over first, then finally, at a much greater capacity, the violet. Critical capacity as a function of

wave-length is well represented by the exponential $e^{\frac{6}{\lambda-\lambda}}$ approaching a constant value in the infra-red and the value infinity in the ultra-violet, perhaps not farther out than $250 \mu \mu$.

Consider the radiation from a nitrogen atom. When subjected to feeble electrical excitation its (primary) spectrum is banded, each band being composed of numerous lines not showing the Zeeman effect. But when subjected to excessive excitation, as it is when a large condenser is connected in shunt with the conducting gas, its (secondary) spectrum consists of numerous heavy lines, showing the Zeeman effect, and expressible in Kayser-Runge series.

Runge, having in mind the Zeeman effect, supposes that primary spectra are due to positive ions while negative electrons give secondary spectra, but it is hardly conceivable that feeble excitation should all go to the positive ions while more intense excitation all goes to the negative.

I would suggest that an atom composed of rotating rings of electrons according to recent theories might easily exhibit just such radiating properties as would give primary and secondary spectra, together with the variation of critical capacity with wave-length. Suppose that there are as many rings as there are bands in the primary spectrum, With moderate excitation these rings would vibrate radially and tangentially as well as perpendicularly to their planes, and these vibrations would give rise to the lines comprising each band. Such lines would not show the Zeeman effect. Excessive excitation would break up the rings and allow the electrons to move independently. Radiation from such free electrons would constitute the secondary spectrum, and would show the full Zeeman effect. The larger rings would be the first to break up; the smallest rings, perhaps, could not be broken up at all, hence critical capacity would vary with the wave-length and become infinite for moderately short waves. Metallic atoms have ring systems that are so easily broken up that it is impossible to obtain any primary spectrum from them at all.

Washington, D.C.

P. G. Nutting.

The Flowering of the Bamboo.

CAN your botanical readers give me any information about the flowering of the bamboo? Until recently I was not aware that it presented any extraordinary features, but about the middle of April the bamboo in this locality produced flowers, to the great astonishment of everyone long resident here. The peasants, and many of the more ignorant townspeople, regarded the event with much superstitious terror. It is supposed by them to portend a failure of the crops, and possibly even more serious disasters. A small anti-tax rising, some distance away, appeared for a few days to be a serious matter, and as it was in progress during the time at which the bamboo flowers appeared, many were inclined to exaggerate enormously the danger of the situation. These superstitious terrors (closely resembling the fears formerly aroused in Europe on the appearance of a large comet) sufficiently show the rarity of the phenomenon.

On making inquiry, I could only hear of one man (I did not myself meet him) who had ever seen the bamboo in flower before.

I am told that a species of bamboo in southern California flowers annually, the flower being at the top of the plant only. In the species growing here the flowers were at all heights, arranged at frequent intervals along almost every branch of the plants. I obtained a photograph of a spray in flower, but unfortunately it is so small that the distinction between leaves and inflorescences is very imperfect.

Imperial Provincial College, Chinanfu, Shantung, China, May.

As regards the point raised by your correspondent, I may say that the feeling of alarm aroused in the natives by the flowering of the bamboo seems to be widely spread in the East. I have myself heard of it when in India.

The fact is that the bamboo only flowers once and then dies, and as a rule the whole lot of plants, often covering large areas, bloom together.

The reason of this is that the individuals of a species are commonly gregarious, and are all of the same age, having taken simultaneous possession of ground rendered vacant, perhaps, by a previous and similar depopulation.

A somewhat analogous case is presented by some of the Strobilanths of tropical Asia. These plants live for about seven years, then all burst out into a glorious mass of blue flower, and then die away, leaving, it may be, hundreds of acres of ground destitute of the luxuriant vegetation it previously supported.

Dr. O. Stapf, in a most interesting article that appeared in the Gardener's Chronicle this year (Nos. 907-910), gives an account of the introduction into Europe of two bamboos that have suffered a similar fate.

In 1847 seeds of Arundinaria Falconeri (and another species) were received at Kew, and were thence distributed to various gardens, some finding their way to the Continent. The plants flowered (and then died) in France in 1875, and in the iollowing year all the English plants, growing in different localities, shared the same fate.

\section{The Organisation of Zoologists.}

MAY I be allowed to direct the attention of the readers of Nature to the fact that a meeting of zoologists will be held in the comparative anatomy lecture room at Cambridge on Wednesday, August 17, at 4 p.m., to consider a scheme for organisation suggested by the committee that was appointed in London on January 4 . The suggested scheme has been printed and widely circulated, but as it may have failed to reach some of the zoologists of the country, $I$ have been requested to state that al! who are interested in zoology and anxious to promote its progress will be welcome.

Sydney J. Hickson.

The Victoria University, Manchester, August 3. 